\title{
Relevancy of Urine Bilirubin with Dandruff
}

\author{
Muhammad Imran Qadir, Usama Razzaq* \\ Institute of Molecular Biology and Biotechnology, Bahauddin Zakariya University, Multan, Pakistan \\ *Corresponding Author: Usama Razzaq, Institute of Molecular Biology and Biotechnology, Bahauddin \\ Zakariya University, Multan, Pakistan, Email: usama.razzaq168@gmail.com
}

\begin{abstract}
The main purpose of this article was to study a relevancy between urine bilirubin and dandruff. Bilirubin is a linear tetra pyrrole molecule having yellowish colour produced during the breakdown of erythrocytes. If bilirubin enters into urine, it is called urine bilirubin. Dandruff is the falling of the dead skin cells from scalp as white dots. Study of Dandruff, its signs, causes and treatment come under the subject of dermatology. It was concluded that male with urine bilirubin quantity $1.1 \mathrm{mg} / \mathrm{dL}$ have more chance of dandruff while female with $0.8 \mathrm{mg} / \mathrm{dL}$ have more chance of dandruff.
\end{abstract}

Keywords: Urine Bilirubin, Liver disease, Dandruff and Dipsticks

\section{INTRODUCTION}

Bilirubin is a linear tetra pyrrole molecule having yellowish colour produced during the breakdown of erythrocytes. If bilirubin enters into urine, it is called urine bilirubin. There are two types of bilirubin: conjugated and nonconjugated bilirubin. Bilirubin test is essential to check whether is quantity is within normal range. Normal urine bilirubin ranges from 0.2$1.2 \mathrm{mg} / \mathrm{dL}$. Life span of red blood cells is 120 days. After this time, erythrocytes hemolyzed to globin and heme molecules.

Globin molecule then hydrolyzed to amino acids while heme converts into iron and bilirubin. Bilirubin formed by the degradation of RBCs then discharged into liver. In case of normal healthy liver, most of the quantity of bilirubin removed from body but in case of liver which is not working normal most of the bilirubin leak into blood and urine. Abnormal functioning of liver includes liver diseases such as jaundice, hepatitis, liver cancer, liver injury and drinking more alcohol. The function of bilirubin is to give urine its original colour. Bilirubin is an insoluble anti-oxidant giving colour to bile, feces, urine and also responsible for the discoloration of skin as in case of jaundice. Home remedies include eating fish, vegetables, olive oil and fruits that can power the liver to function normally.

Dandruff is the falling of the dead skin cells from scalp as white dots. Study of Dandruff, its signs, causes and treatment come under the subject of dermatology. Signs of dandruff include flakes, itchy, inflammation and scaly scalp. Causes of dandruff includes growth of yeast like fungus malassezia, sebaceous gland secretion, environmental factors, dust, pollution, excessive use of hair-styling products, individual susceptibility, taking stress and eating food not containing essential vitamins. Dandruff is treated with shampoos and also with home remedies. Trichorganic anti-dandruff shampoo is effect against dandruff. Its main components are ketoconazole and itchthyol pale. Ketoconazole has anti-fungal properties, it prohibits the compilation of ergo sterol. Ergo sterol is a fundamental component of fungal cell membrane. It chthyol pale has multi antidandruff characters as it has anti-microbial, antifungal and anti-irritant characters. Its usage slows down the enhanced growth of skin cells on scalp. Home remedies include the use of vitamin E, Castrol oil and yogurt. Castrol oil is composed of omega-9 fatty acids. Applying Castrol oil on hairs improves the hydration of hair and scalp and cure dandruff symptoms. Yogurt is rich in protein provides essential nutrients to hairs and help the hair follicle to grow.

The main purpose of this article was to study a relevancy between urine bilirubin and dandruff.

\section{MATERIAL AND MethodS}

For the measurement of urine bilirubin, first of all dip the test strip into the container containing urine. The test strips should be submerged for a 
few seconds and the ends of strips not touch each other to prevent cross-contamination. The color then compare with the dipsticks which counts the reading of urine bilirubin.

\subsection{Statistical Analysis}

Statistical analysis was performed on the Microsoft office word by counting the percentage.

\section{RESULTS AND DISCUSSION}

Table1: Relevancy between urine bilirubin and dandruff

\begin{tabular}{|l|l|l|l|}
\hline Gender & $\mathbf{0 . 2} \mathbf{~ m g} / \mathbf{d L}$ & $\mathbf{0 . 8} \mathbf{~ m g} / \mathbf{d L}$ & \multicolumn{1}{|c|}{$\mathbf{~ m g / d L}$} \\
\hline Male & $5 \%(\mathrm{~N}-\mathrm{D})$ & $20 \%(\mathrm{~N}-\mathrm{D})$ & $40 \%(\mathrm{D})$ \\
\hline Female & $0 \%(\mathrm{~N}-\mathrm{D})$ & $20 \%(\mathrm{D})$ & $15 \%(\mathrm{~N}-\mathrm{D})$ \\
\hline
\end{tabular}

"D" indicate those people that have dandruff symptoms while "N-D" indicates the percentage of those people not having dandruff symptoms. Table no: 01 indicates the relevancy of urine bilirubin with dandruff. Male with urine bilirubin quantity $1.1 \mathrm{mg} / \mathrm{dL}$ have more chance of dandruff while female with $0.8 \mathrm{mg} / \mathrm{dL}$ have more chance of dandruff.

\section{CONClusion}

It was concluded that male with urine bilirubin quantity $1.1 \mathrm{mg} / \mathrm{dL}$ have more chance of dandruff while female with $0.8 \mathrm{mg} / \mathrm{dL}$ also have more chance of dandruff.

\section{REFERENCES}

[1] Qadir MI, Malik SA (2010) Comparison of alterations in red blood cell count and alterations in hemoglobin concentration in patients suffering from rectal carcinoma undergoing 5-fluorouracil and folic acid therapy. Pharmacology online, Nl 3: 240-243.

[2] Qadir MI, Noor A (2018) Anemia's. Rare \& Uncommon Diseases. Cambridge Scholars Publishing. Newcastle, England. ISBN: 978-15275-1807-0.

[3] Qadir MI, Javid A (2018) Awareness about Cohn's Disease in biotechnology students. GloAdv Res J Med Medical Sci, 7(3): 062-064.

[4] Qadir MI, Saleem A (2018) Awareness about ischemic heart disease in university biotechnology students. GloAdv Res J Med Medical Sci, 7(3): 059-061.

[5] Qadir MI, Ishfaq S (2018) Awareness about hypertension in biology students. Int $\mathrm{J}$ Mod Pharma Res, 7(2): 08-10.

[6] Qadir MI, Mehwish (2018) Awareness about psoriasis disease. Int J Mod Pharma Res, 7(2): 17-18.

[7] Qadir MI, Shahzad R (2018) Awareness about obesity in postgraduate students of biotechnology. Int J Mod Pharma Res, 7(2): 14-16.

[8] Qadir MI, Rizvi M (2018) Awareness about thalassemia in post graduate students. MOJ Lymphology\&Phlebology, 2(1): 14-16.

[9] Qadir MI, Ghalia BA (2018) Awareness survey about colorectal cancer in students of M. Phil Biotechnology at Bahauddin Zakariya University, Multan, Pakistan. Nov Appro in Can Study, 1(3): NACS.000514.2018.

[10] Qadir MI, Saba G (2018) Awareness about intestinal cancer in university student. Nov ApproinCanStudy, 1(3): NACS.000515.2018.

Citation: Muhammad Imran Qadir, Usama Razzaq, Relevancy of Urine Bilirubin with Dandruff. ARC Journal of Dermatology. 2019; 4(1):7-8. doi:dx.doi.org/10.20431/2456-0022.0401002.

Copyright: () 2019 Authors. This is an open-access article distributed under the terms of the Creative Commons Attribution License, which permits unrestricted use, distribution, and reproduction in any medium, provided the original author and source are credited. 